\title{
Perfluorochemical Liquids Enhance Delivery of Superoxide Dismutase to the Lungs of Juvenile Rabbits
}

\author{
LUCA BRUNELLI, ERIC HAMILTON, JONATHAN M. DAVIS, HSHI-CHI KOO, ANSAMMA JOSEPH, JEFFREY A. KAZZAZ, \\ MARLA R. WOLFSON, AND THOMAS H. SHAFFER
}

\begin{abstract}
Division of Neonatology [L.B.], Thomas Jefferson University, Philadelphia, Pennsylvania 19107; Department of Pediatrics [L.B.], University of Turin, Turin 10126, Italy; Departments of Physiology and Pediatrics [E.H., M.R.W., T.H.S], Temple University School of Medicine, Philadelphia, Pennsylvania 19140; Division of Neonatology [H.-C.K., A.J., J.M.D., J.A.K.], Cardiopulmonary Research Institute, Winthrop University Hospital-SUNY Stony Brook School of Medicine, Mineola, New York 11501; Nemours Lung Center [T.H.S.],

A. I. duPont Hospital for Children, Wilmington, Delaware 19803
\end{abstract}

\begin{abstract}
Previous studies suggest acute lung injury (ALI) in premature newborns is associated with relative deficiency of antioxidant enzymes that may be ameliorated by recombinant human superoxide dismutase (rhSOD). Perfluorochemicals (PFCs) are distributed homogeneously and support gas exchange in diseased lungs. We investigated whether PFCs could provide an effective delivery system for rhSOD. Juvenile rabbits were lung-lavaged, treated with surfactant, and randomized: group I: fluorescently labeled rhSOD (5 $\mathrm{mg} / \mathrm{kg}$ in $2 \mathrm{~mL} / \mathrm{kg}$ saline); group II: fluorescently labeled $\mathrm{rhSOD}(5$ $\mathrm{mg} / \mathrm{kg}$ in $18 \mathrm{~mL} / \mathrm{kg}$ PFC). Animals were ventilated with oxygen for $4 \mathrm{~h}$; the lungs were harvested for analysis of SOD distribution and oxidative injury. Cardiopulmonary indices remained stable and similar between groups. Qualitative assessment (QA) showed a more homogeneous lung SOD distribution in group II and a better histologic profile. QA of lung SOD distribution showed significant increase in SOD concentrations in group II $(7.37 \pm 1.54 \mu \mathrm{g} / \mathrm{mg}$ protein) compared with group I (1.65 $\pm 0.23 \mu \mathrm{g} / \mathrm{mg}$ protein). Oxidative injury as assessed by normalized protein carbonyl was 149.1 $\pm 26.8 \%$ SEM in group II compared with $200.5 \pm 7.3 \%$ SEM in group I. Plasma SOD was significantly higher in group II. Administration of rhSOD with or without PFCs does not compromise cardiovascular function or impede lung recovery after ALI. PFCs enhance rhSOD delivery to the lungs by $400 \%$ while decreasing lung oxidative damage by $25 \%$ compared with rhSOD alone. These data suggest that PFCs optimize lung rhSOD delivery and might enhance the beneficial effects of rhSOD in preventing acute and chronic lung injury. (Pediatr Res 60: 65-70, 2006)
\end{abstract}

$\mathrm{P}$ reterm infants have incomplete structural lung development, rendering the lung prone to oxygen-mediated toxicity. Furthermore, the lung is uniquely exposed to higher oxygen tensions compared with most organs. Room air oxygen tension in the alveolus is approximately $100 \mathrm{~mm} \mathrm{Hg}$ compared with $45 \mathrm{~mm} \mathrm{Hg}$ in venous blood and as low as 1 $\mathrm{mm} \mathrm{Hg}$ in some sites within other organs. The molecular mechanisms responsible for oxygen toxicity include formation

Received February 11, 2005; accepted March 2, 2006.

Correspondence: Thomas H. Shaffer, Ph.D., Nemours Research Lung Center, Alfred I duPont Hospital for Children, 1600 Rockland Road, A/R 308-B, Wilmington, DE 19803; e-mail: tshaffer@nemours.org.

Supported in part by grant HL-64158 from the National Institutes of Health, Heart, Lung, and Blood Institute and NIH COBRE grant 1 P20 RR20173-01 (Center for Pediatric Research at Nemours).

DOI: $10.1203 / 01 . p d r .0000219392 .73509 .70$ of free radical intermediates and the subsequent damage of lung proteins, lipids, and DNA (1).

To counteract the detrimental effects of oxygen, a number of antioxidant systems have evolved. The antioxidant enzymes catalase, glutathione peroxidase, and SOD are strategic components of such complex defense mechanisms. SOD is capable of converting the toxic superoxide anion radical to potentially less toxic hydrogen peroxide and water. Three SOD isoenzymes have been identified in mammals. The major intracellular SOD is a low molecular weight copper/zinccontaining protein $(\mathrm{Cu} / \mathrm{Zn} \mathrm{SOD})$ present in the cytoplasm of all mammalian cells (2). Mitochondrial SOD (MnSOD) is a manganese-containing protein that is synthesized in the cytoplasm and translocated to the mitochondria (3). The last mammalian SOD discovered is a high molecular weight $\mathrm{Cu} /$ $\mathrm{Zn}$-containing protein primarily located in extracellular spaces (EC-SOD) (4).

The premature lung lacks not only the late gestational maturation of the surfactant system, but also the antioxidant enzyme systems. The lungs of different animal species show a dramatic rise in activity of the major antioxidant enzymes around the time of birth $(5,6)$. Human studies show a similar developmental trend $(7,8)$. Furthermore, at least in the rabbit, only term animals are capable of up-regulating enzymatic antioxidant expression when faced with oxygen stress (9). Therefore, it appears attractive to supplement the lung with SOD in an attempt to modulate oxidant stress and injury around the time of birth.

rhSOD is a human recombinant $\mathrm{Cu} / \mathrm{Zn}$ SOD that has been shown to ameliorate ALI and chronic lung injury in animal studies $(10,11)$. Two placebo-controlled pilot studies have been conducted in premature infants with respiratory distress syndrome using single or multiple intratracheal doses of rhSOD $(12,13)$. These studies have established pharmacoki-

Abbreviations: ALI, acute lung injury; $\mathbf{C}_{\mathbf{R}}$, respiratory compliance; $\mathbf{O I}$, oxygenation index; PEEP, positive end-expiratory pressure; PFC, perfluorochemical; PIP, peak inspiratory pressure; rhSOD, recombinant human $\mathrm{CuZn}$ superoxide dismutase; VEI, ventilation efficient index 
netic profiles and short-term safety for rhSOD. They have also suggested that rhSOD might reduce the early lung inflammatory changes associated with the subsequent development of bronchopulmonary dysplasia (BPD). Subsequent studies have suggested that rhSOD may improve long-term pulmonary and neurodevelopmental outcome in critically ill preterm neonates $(14,15)$. One central factor during the rhSOD clinical trials was that intratracheal rhSOD administration was not always well tolerated by extremely preterm infants. Furthermore, because rhSOD was administered in a saline suspension using small volumes, it was unlikely that the rhSOD was distributed homogeneously to the entire lung.

PFC liquids offer potential for biomedical use and ventilatory support. PFC fluids act as a vehicle for delivering oxygen and removing carbon dioxide (16,17). Air-liquid interfaces are eliminated, thereby increasing lung compliance and recruiting alveoli. PFC liquids can be distributed homogeneously throughout the lungs at low pressures because of low surface tension properties. Furthermore, PFC liquids are biologically inert and appear to have no deleterious histologic, cellular, or biochemical effects (18). There are several commercially available PFC fluids with physicochemical properties and purity specifications appropriate for respiratory applications $(19,20)$. Our laboratory has shown that PFC fluids are attractive respiratory media for pulmonary administration of various drugs $(19,20)$. Therefore, PFC liquids may provide an excellent vehicle for the distribution of rhSOD while simultaneously supporting gas exchange in an already diseased lung.

In the current study, we hypothesized that rhSOD could be safely administered either with or without PFCs in our juvenile rabbit model of ALI. Also, we examined whether PFCmediated administration of rhSOD would enhance lung distribution of the enzyme and, in the short term, decrease markers of oxidative damage. Finally, physiologic and histologic comparisons of SOD treatment groups are discussed within the context of published data from untreated animals and those treated with PFC alone (21-27).

\section{METHODS}

Animals were managed according to the National Institutes of Health regulations "Guide for the Care and Use of Laboratory Animals". In addition, all procedures were approved by the Institutional Animal Care Use of Temple University.

Animal preparation. Twelve New Zealand White juvenile rabbits $(8-10$ wk old; weight, $1.3-2.1 \mathrm{~kg}$ ) with normal lungs were anesthetized with an intramuscular injection of a mixture of ketamine $(23 \mathrm{mg} / \mathrm{kg})$, acepromazine $(0.58 \mathrm{mg} / \mathrm{kg})$, and xylazine $(0.8 \mathrm{mg} / \mathrm{kg})$ and an intramuscular injection of atropine $(0.02 \mathrm{mg} / \mathrm{kg})$ was given. This animal model was chosen based on our previous experience with the model, the suitability of the model as it applies to neonatal and pediatric medicine, and the history of this preparation for liquid ventilation (21-25). The skin and soft tissues were anesthetized with $0.5 \%$ lidocaine $\mathrm{HCl}(4 \mathrm{mg} / \mathrm{kg})$, and the animals were instrumented with tracheostomy placement of a 3-mm-internal diameter endotracheal tube (Hi-Lo Jet Tube: Mallinkrodt, St. Louis, MO). Catheters were placed in the jugular vein and carotid artery. Anesthesia was maintained with an i.v. injection of sodium pentobarbital $5 \mathrm{mg} / \mathrm{kg}$ as needed or hourly. Muscle relaxation was induced by i.v. administration of pancuronium bromide $(0.1$ $\mathrm{mg} / \mathrm{kg}$ ) and maintained with a continuous infusion of $0.15 \mathrm{mg} / \mathrm{kg} / \mathrm{h}$ throughout the experiments. Maintenance fluids were provided by a continuous infusion of $5 \%$ dextrose at a rate of $5 \mathrm{~mL} / \mathrm{kg} / \mathrm{h}$. Arterial blood pressure was monitored by attaching the arterial catheter to a standard pressure transducer connected to a neonatal monitor (Athena/Neonatal 9040, S \& W Medico Teknik, Albertslund, Denmark). ECG electrodes and a rectal temperature probe were inserted for monitoring. The animal's rectal temperature was maintained at $37-38^{\circ} \mathrm{C}$

Tidal volume and respiratory compliance $\left(\mathrm{C}_{\mathrm{R}}\right)$ were measured (Peds MAS, Hatfield, PA) with pneumotachography and airway manometry $(21,26)$. Arterial blood gases (Stat profile, Nova Biomedical, Waltham, MA) were also measured in all groups.

Mechanical ventilation was provided with a time-cycled, pressure-limited ventilator (V.I.P. BIRD Gold, Bird Products Corp.) and adjusted to maintain a tidal volume of $6 \mathrm{~mL} / \mathrm{kg}$ and to keep the arterial $\mathrm{pCO}_{2}$ below $60 \mathrm{~mm} \mathrm{Hg}(7.9$ $\mathrm{kPa})$. The inspired oxygen fraction was maintained at 1.0 throughout the experiment. Initial and maximal values for the remaining settings were peak inspiratory pressure (PIP) of $1.1-3 \mathrm{kPa}\left(11-30 \mathrm{~cm} \mathrm{H}_{2} \mathrm{O}\right)$; frequency of 30-60 breaths/min; inspiratory time of $0.3-0.5 \mathrm{~s}$; and positive end-expiratory pressure (PEEP) of $0.4-0.8 \mathrm{kPa}\left(4-8 \mathrm{~cm} \mathrm{H}_{2} \mathrm{O}\right)$. The PFC liquid was a mixture of $25 \%$ perfluoromethylcyclohexane (PP2) and $75 \%$ perfluoromethyldecalin (PP9) (F2 Chemicals Corp., Preston, U.K.). This mixture provides better gas exchange, compliance, and histologic findings after ALI as described in our laboratory (27).

Protocol. After obtaining baseline data for arterial blood gases, ventilatory parameters, pulmonary function tests, and physiologic parameters in all animals, lung injury was induced by repeated lung lavage with $10 \mathrm{~mL} / \mathrm{kg}$ of warm normal saline until injury criteria were achieved: arterial $\mathrm{Po}_{2}<100 \mathrm{~mm}$ $\mathrm{Hg}(13.3 \mathrm{kPa})$ with a $\mathrm{C}_{\mathrm{R}}$ decreased by more than $50 \%$ and less than 0.5 $\mathrm{mL} / \mathrm{cm} \mathrm{H}_{2} \mathrm{O} / \mathrm{kg}$ maintained for more than $30 \mathrm{~min}$ (21). All animals were treated with $4 \mathrm{~mL} / \mathrm{kg}$ of surfactant (Survanta ${ }^{\circledR}$, Ross Laboratories, Columbus, $\mathrm{OH})$ and then randomly assigned to one of two groups: group I, treated with rhSOD $(5 \mathrm{mg} / \mathrm{kg})$ suspended in saline $(2 \mathrm{~mL} / \mathrm{kg})$, and group II, treated with rhSOD $(5 \mathrm{mg} / \mathrm{kg})$ suspended in PFC $(18 \mathrm{~mL} / \mathrm{kg})$. rhSOD was given in all animals within $10 \mathrm{~min}$ after surfactant administration. Half the animals in each group received rhodamine-conjugated rhSOD. We have previously reported physiologic and histologic data from this lung injury model over $4 \mathrm{~h}$ in an untreated mechanically ventilated group, as well as a PFC (25\% PP2/75\% PP9) alone group $(21,27)$.

The rhSOD/PFC suspension was instilled into the lungs via the side port of the endotracheal tube over 5-10 min. During instillation, the animals were repositioned to optimize PFC distribution using four equal increments of the total dose with Trendelenburg, reverse Trendelenburg, and left and right lateral decubitus positions. After instillation, the animal position (supine), airway temperature $\left(35^{\circ} \mathrm{C}\right)$, and humidity $(100 \%)$ were kept constant. The arterial blood gases, ventilatory parameters, pulmonary function tests, and physiologic data were measured and/or recorded again after lung injury and then every $30 \mathrm{~min}$ for $4 \mathrm{~h}$ or until death.

The oxygenation index (OI) and the ventilation efficient index (VEI) were computed as described $(21,28,29):$ OI $=[$ mean airway pressure $\times$ inspired oxygen fraction $\left.) / \mathrm{PO}_{2}(\mathrm{~mm} \mathrm{Hg})\right] \times 100 ; \mathrm{VEI}=3800 /[$ respiratory rate $(\mathrm{PIP}-$ PEEP) $\times \mathrm{PCO}_{2}(\mathrm{~mm} \mathrm{Hg})$ ], where VEI relates alveolar ventilation to respiratory input, and 3800 is a constant for estimating alveolar ventilation (3800/ $\mathrm{PCO}_{2}$ ) with the assumption of $\mathrm{CO}_{2}$ production near normal minimal volumes of $5 \mathrm{~mL} / \mathrm{kg} / \mathrm{min}$ in resting animals.

At the end of the experiments, the animals were euthanized with sodium pentobarbital. The thorax was opened, and the lungs were inspected to assess gross morphology. Within $5 \mathrm{~min}$ of death, the ventilator was stopped and continuous positive airway pressure equivalent to the final PEEP was applied. Lungs were immediately perfused with Millinogs buffer, and samples within the dependent and nondependent regions of the lungs were obtained (0.5- to $1.0-\mathrm{cm}^{3}$ blocks) and snap frozen for qualitative and quantitative analysis of rhSOD distribution and lung oxidative injury as assessed by protein carbonyls.

rhSOD/PFC suspension. The creation of nanocrystal suspensions of rhSOD with PFC fluids was carried out as described (30). Briefly, the suspensions were made by combining $5 \mathrm{mg} / \mathrm{kg}$ rhSOD with $18 \mathrm{~mL} / \mathrm{kg}$ of $25 \%$ $\mathrm{PP} 2 / 75 \% \mathrm{PP} 9$ in an ultrasonic unit (Bronson B-220H) for 5-10 min.

SOD analyses. Lung homogenates or plasma samples were incubated with $\sim 20,000 \mathrm{cpm}$ of ${ }^{125}$ I-rhSOD and a mouse anti-rhSOD1 monoclonal antibody at room temperature followed by an overnight incubation at $4^{\circ} \mathrm{C}$. Rabbit anti-mouse serum was added and incubated for at room temperature. Antibody-SOD complexes were precipitated by the addition of $20 \%$ PEG, incubation at room temperature, and centrifugation. Counts were determined using a gamma counter.

Protein carbonyl analyses. Proteins were extracted from lung homogenates and yield determined using the Bio-Rad assay. An aliquot of each sample was derivatized with 2.4-dinitrophenylhydrazine (DNP). Serial dilutions of DNP-derived and nonderived were dot blotted on to nylon membranes. Dot blots were incubated with an anti-DNP polyclonal antibody followed by a HRP-conjugated secondary antibody per the manufacturer's instructions (Intergen Co). Antibody complexes were detected by chemiluminescence and visualized on X-ray film. Films were scanned, and densitom- 
etry was determined using the Sigmagel program. Values were normalized to nonderived protein.

Histomorphometric analysis. Tissues were formalin fixed and embedded in paraffin. Thin sections $(5 \mu \mathrm{m})$ were cut and stained with hematoxylin and eosin. The specimens were analyzed qualitatively with gross light microscopy at $\times 100$ magnification as described (31).

Statistics. One-way analysis of variance (ANOVA) was used to compare basic physiologic data among groups. A paired $t$ test was used to compare preand postinjured data within groups. Two-way repeated measures ANOVA was used to compare data of gas exchange, OI, and respiratory compliance as a function of time and group. Post hoc testing with the Student-NewmanKeuls test was used to determine significance. Significance was accepted at the $p<0.05$ level. Values are presented as mean \pm SEM.

\section{RESULTS}

As shown in Table 1, body weights and the number of saline lavages did not differ significantly between groups. Saline lavage resulted in a similar pattern of lung injury in both studied groups. The values of postinjury OI, VEI, and $C_{R}$ were significantly $(p<0.05)$ different from their corresponding preinjury values for each group (Table 1). The heart rate showed significant increase at the time of injury and/or $1 \mathrm{~h}$ after injury (Table 2). However, there was no significant difference between groups (Table 2). Mean blood pressure remained stable with no significant difference between groups (Table 3). $\mathrm{C}_{\mathrm{R}}$, OI, $\mathrm{PaO}_{2}$, and $\mathrm{PaCO}_{2}$ were not significantly different at the various times between the two experimental groups (Fig. 1). $\mathrm{C}_{\mathrm{R}}$, OI, and $\mathrm{PaO}_{2}$ postinjury were significantly different compared with preinjury values in both groups $(p<$ 0.01 ). OI and $\mathrm{PaO}_{2}$ then improved significantly by $4 \mathrm{~h}$ in both groups $(p<0.01)$.

Representative regional histomicrographs of the lung are presented in Figure 2. As shown, both groups (Fig. 2A and $B$ ) demonstrated a significant degree of injury associated with saline lavage; however, the rhSOD/saline delivery group (Fig. $2 A)$ demonstrated more marked atelectasis and inflammatory cell infiltration. In contrast, there appeared to be less atelectasis and inflammation in the rhSOD/PFC group (Fig. 2B). Grossly, there was a greater number of open exchange units in sections from the rhSOD/PFC animals compared with the animals breathing rhSOD/saline.

Qualitative assessment of lung SOD by fluorescent microscopy of the rhodamine-conjugated rhSOD lung sections showed a more homogeneous and abundant distribution in the rhSOD/PFC group both within and between lung regions

Table 1. Characteristics of animals pre-and post-injury of lungs

\begin{tabular}{lcc} 
& $($ mean $\pm S E)$ & \\
\hline & Group I $(n=6)$ & Group II $(n=6)$ \\
\hline Body weight $(\mathrm{kg})$ & $1.85 \pm 0.10$ & $1.79 \pm 0.15$ \\
No. of lavages & $5 \pm 1$ & $5 \pm 1$ \\
Pre-injury & $1.1 \pm 0.2$ & $1.1 \pm 0.2$ \\
OI & $0.38 \pm 0.15$ & $0.33 \pm 0.13$ \\
VEI & $0.99 \pm 0.14$ & $1.05 \pm 0.23$ \\
C $_{\mathrm{R}}$ & & \\
Post-injury & $15.7 \pm 6.1^{*}$ & $17.8 \pm 8.0^{*}$ \\
OI & $0.11 \pm 0.03^{*}$ & $0.08 \pm 0.03^{*}$ \\
VEI & $0.35 \pm 0.05^{*}$ & $0.34 \pm 0.10^{*}$ \\
$\mathrm{C}_{\mathrm{R}}$ &
\end{tabular}

Values are mean \pm SEM. Group I: + SOD; group II: + SOD/PFC.

$* p<0.05 v s$ corresponding data of pre-injury. No significant difference between groups.
Table 2. Heart rate (beats/min) in the two treatment groups (mean $\pm S E)$

\begin{tabular}{lcc}
\hline & Group I $(n=6)$ & Group II $(n=6)$ \\
\hline Baseline & $199 \pm 13$ & $190 \pm 23$ \\
Injury & $190 \pm 30$ & $233 \pm 16^{*}$ \\
1 h & $218 \pm 21^{*}$ & $230 \pm 17^{*}$ \\
$2 \mathrm{~h}$ & $207 \pm 36$ & $209 \pm 14$ \\
$3 \mathrm{~h}$ & $197 \pm 30$ & $202 \pm 17$ \\
$4 \mathrm{~h}$ & $192 \pm 49$ & $200 \pm 39$ \\
\hline
\end{tabular}

Values are mean \pm SEM. Group I: + SOD; group II: + SOD/PFC. No significant difference between groups.

$* p<0.01 v s$ corresponding baseline data.

Table 3. Mean blood pressure $(\mathrm{mm} \mathrm{Hg})$ in the two treatment groups (mean $\pm S E$ )

\begin{tabular}{lcc}
\hline & Group I $(n=6)$ & Group II $(n=6)$ \\
\hline Baseline & $55 \pm 8$ & $57 \pm 10$ \\
Injury & $76 \pm 4^{*}$ & $76 \pm 5^{*}$ \\
$1 \mathrm{~h}$ & $75 \pm 8$ & $65 \pm 9$ \\
$2 \mathrm{~h}$ & $72 \pm 7$ & $68 \pm 3$ \\
$3 \mathrm{~h}$ & $70 \pm 8$ & $68 \pm 10$ \\
$4 \mathrm{~h}$ & $74 \pm 18$ & $62 \pm 16$ \\
\hline
\end{tabular}

Values are mean \pm SEM. Group I: + SOD; group II: + SOD/PFC. No significant difference between groups.

$* p<0.01 v s$ corresponding baseline data.
A

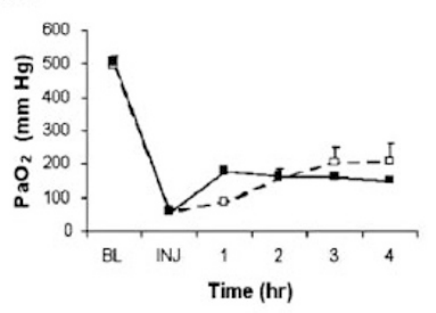

C

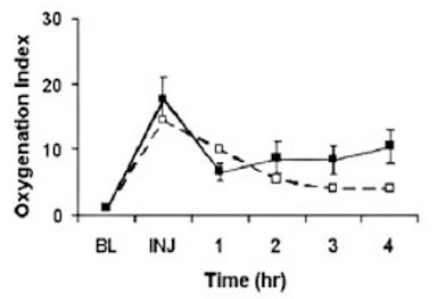

B

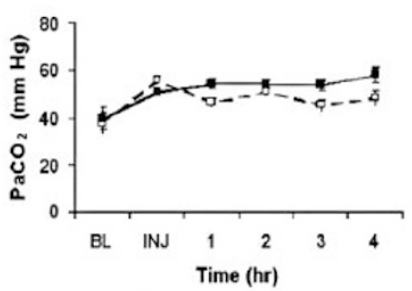

D

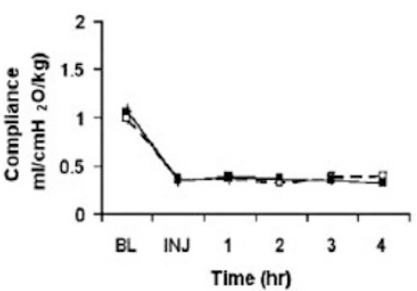

Figure 1. $\mathrm{PaO}_{2}(A)$ and $\mathrm{PaCO}_{2}(B)$ Arterial blood gas measurements pulmonary, OI $(C)$, and pulmonary compliance $(D)$ in animals administered rhSOD $(\square)$ in saline vs SOD/PFC (ם) suspension. Values are expressed as mean \pm SEM. To convert $\mathrm{mm} \mathrm{Hg}$ to $\mathrm{kPa}$, multiply the value by 0.1333 . SOD group, $n=6$; SOD/PFC group, $n=6$. No significant differences were noted between groups.

compared with the rhSOD/saline group. Figure $2 C$ and $D$ are representative illustrations of such findings. Quantitative analysis of overall lung SOD distribution showed a significant increase in SOD concentrations in the rhSOD/PFC group (7.37 $\pm 1.54 \mu \mathrm{g} / \mathrm{mg}$ protein) compared with the rhSOD group $(1.65 \pm 0.23 \mu \mathrm{g} / \mathrm{mg}$ protein) $(p<0.01)$ (Fig. 3).

Lung oxidative damage, as expressed by the normalized overall protein carbonyl, was $149.1 \pm 26.8 \%$ SEM in the $\mathrm{rhSOD} / \mathrm{PFC}$ group compared with $200.5 \pm 7.3 \%$ SEM in the rhSOD group $(p<0.03)$ (Fig. 4). 


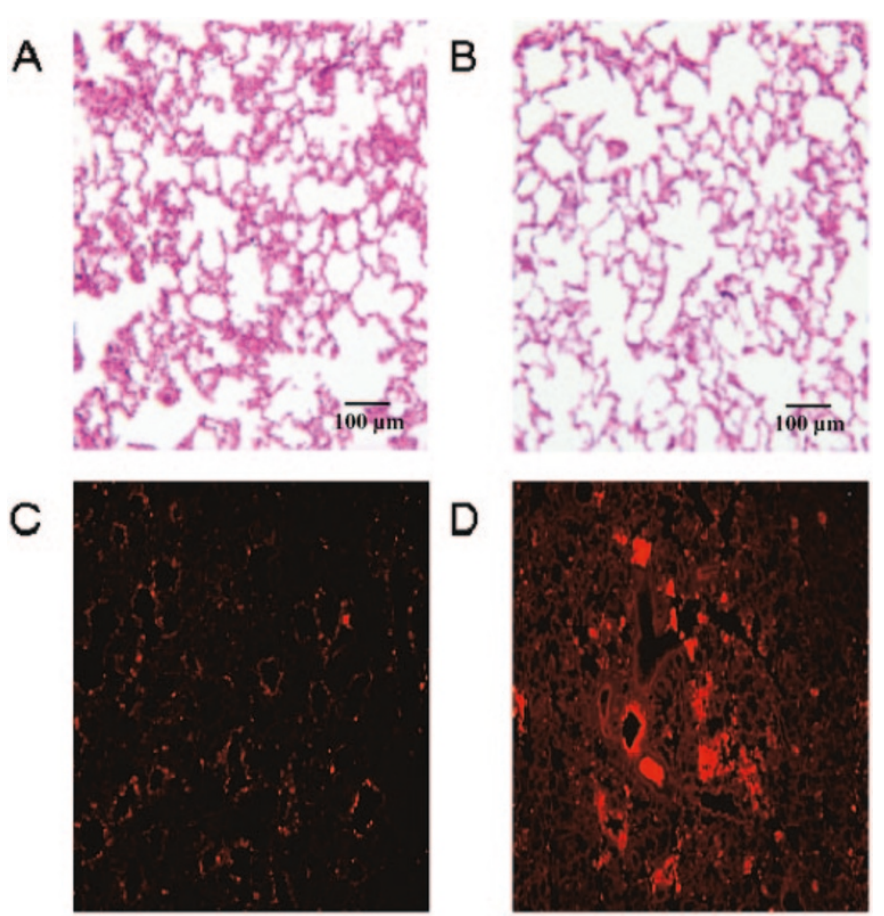

Figure 2. Histomicrographs illustrating qualitative assessment of lung expansion by light microscopy of hematoxylin/eosin-stained lung sections $(A, B)$ and rhSOD distribution by fluorescent microscopy of rhodamine-conjugated rhSOD lung sections $(C, D)$. Lung sections are representative of typical patterns observed over many different lung sections. $A$ and $C$ : Saline-delivered SOD. $B$ and $D$ : PFC suspension of SOD $(\times 100$ magnification).

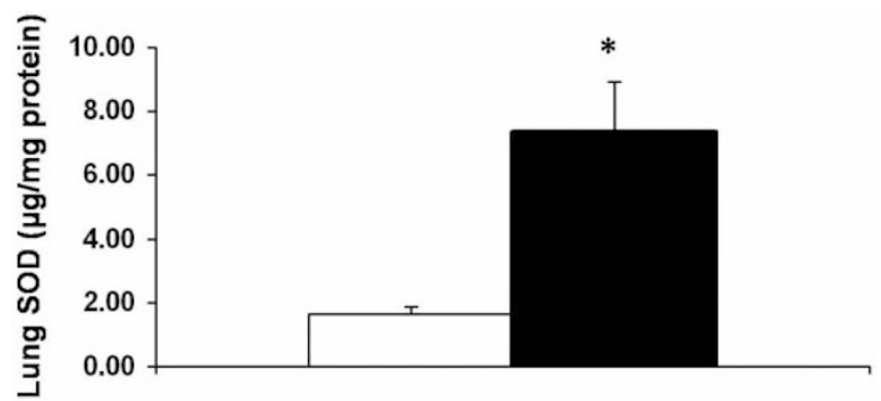

Figure 3. Quantitative lung rhSOD $(\mu \mathrm{g} / \mathrm{mg})$ distribution $[+$ SOD (open column); $+\mathrm{SOD} / \mathrm{PFC}$ (solid column)]. Values are expressed as mean $\pm \mathrm{SEM}$. ${ }^{*} p<0.01$ vs SOD group.

Plasma SOD at $4 \mathrm{~h}$ was $3.30 \pm 0.55 \mu \mathrm{g} / \mathrm{mL}$ in the rhSOD/ PFC group compared with $1.45 \pm 0.64 \mu \mathrm{g} / \mathrm{mL}$ in the $\mathrm{rhSOD}$ group ( $p<0.05$ ) (Fig. 5).

When evaluating oxidative injury and tissue SOD over a matched SOD range between 0 and $5 \mu \mathrm{g} / \mathrm{mg}$ protein, only $8 \%$ of lung sections in the rhSOD group had a protein carbonyl below the normalized $100 \%$ level compared with $22 \%$ in the rhSOD/PFC group (Fig. 6). This indicates a three times likelihood that a lung section in the rhSOD/PFC group with an SOD level below $5 \mu \mathrm{g} / \mathrm{mg}$ protein would have a normalized protein carbonyl level below 100\% compared with the rhSOD group.

\section{DISCUSSION}

Initial clinical attempts at augmenting the antioxidant defenses of the premature lung have been encouraging (12-15).

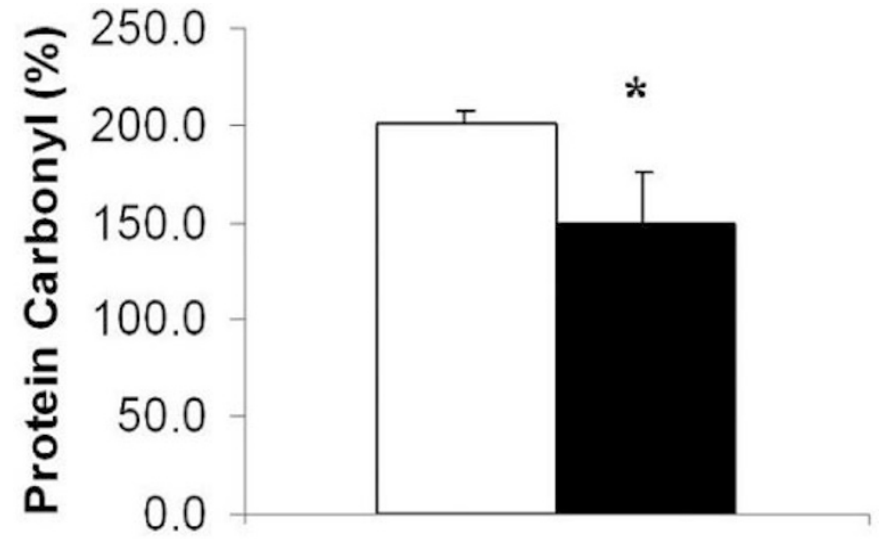

Figure 4. Lung oxidative damage expressed as normalized lung protein carbonyl (\%) level [+ SOD (open column); + SOD/PFC (solid column)]. Values are expressed as mean \pm SEM. $* p<0.01$ vs SOD group.

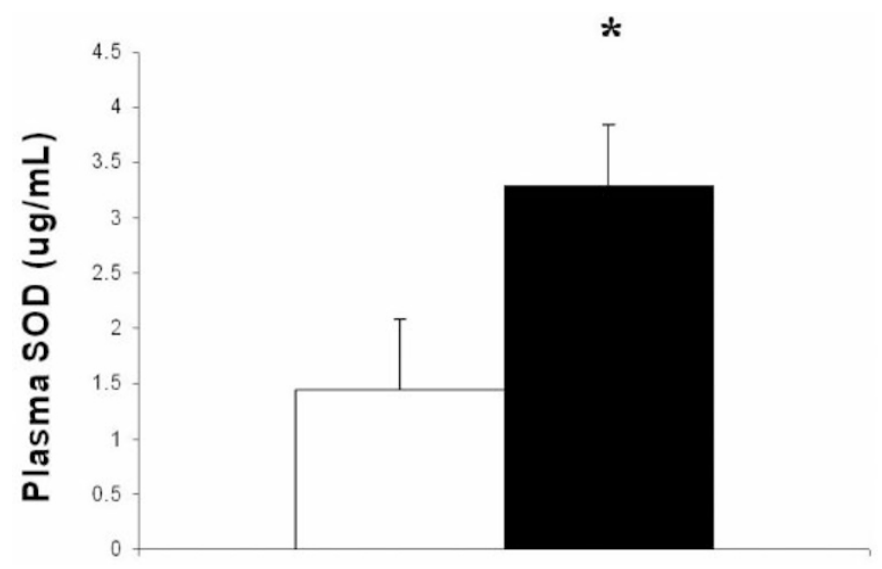

Figure 5. Quantitative rhSOD levels $(\mu \mathrm{g} / \mathrm{mL})$ in plasma at $4 \mathrm{~h}$ post-delivery [+ SOD (open column); + SOD/PFC (solid column)]. Values are expressed as mean \pm SEM. $* p<0.01 v s$ SOD group.

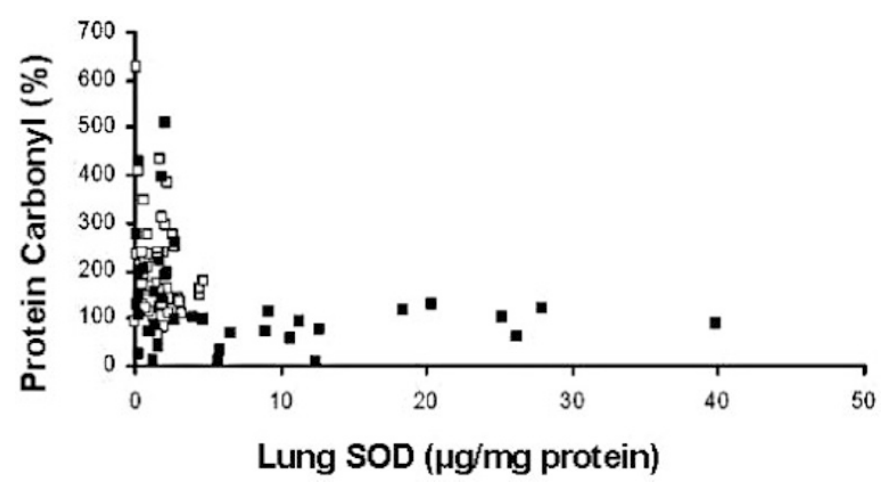

Figure 6. Relationship between oxidative injury protein carbonyls (PC) and tissue rhSOD over a matched SOD range between 0 and $5 \mu \mathrm{g} / \mathrm{mg}$ protein. + SOD ( $\square$ ); + SOD/PFC (ם). The curve represents the best fit regression analysis.

One central factor evident during these clinical trials was that some extremely premature infants did not tolerate intratracheal rhSOD administration well. Furthermore, it was unlikely that rhSOD in a small-volume saline suspension would distribute homogeneously to the entire lung, which may have had a negative impact on pulmonary outcome. In the current study, we demonstrated that rhSOD can be safely administered either with or without PFC in a juvenile rabbit model of ALI treated 
with surfactant to simulate clinical management. Importantly, we showed that the PFC-mediated administration of rhSOD allows a more homogeneous distribution of the enzyme accompanied by a synergistic decrease in lung oxidative damage. Taken together, these findings suggest that PFC might optimize rhSOD delivery, better expand and recruit the lung, and enhance the beneficial effects of rhSOD after ALI.

The lung is exposed to high oxygen tensions compared with other organs and is therefore particularly prone to oxidant stress. Oxidative stress triggers inflammatory mediators thus activating neutrophils and alveolar macrophages (32). Such inflammatory changes may be the link between ALI and the development of chronic lung disease. When such events occur, improvements in lung function will require significant amounts of time to occur. Our study was carried out over a short time period, and it should be noted that we did not observe any improvement in lung physiology in the rhSOD/ PFC group compared with the rhSOD alone group despite less oxidative damage and an improved histologic profile. We can speculate that less oxidative injury and better lung expansion in the rhSOD/PFC group may translate over time to improved physiologic lung parameters. However, to confirm this issue, studies of longer duration are warranted to determine whether rhSOD could protect surfactant from oxidative injury and result in physiologic improvements in lung function.

More recently, the combination of two PFC fluids has been shown to be particularly effective for treatment of ALI (27). As shown in this study, the rhSOD/PFC group had similar physiologic and histologic profiles as in previously treated PFC (25\% PP2/75\% PP9) alone groups (27). Compared with untreated lung-injured rabbits (21), groups treated with $\mathrm{PFC}$ alone, rhSOD/PFC, or rhSOD/saline demonstrated better gas exchange and lung function over the 4-h study period. In addition to the favorable physiologic and histologic outcomes, combinations of PFC liquids and drugs have proven very effective in promoting the nanocrystal suspension of biologic agents in the lungs (30). Here we show that such PFC combination promotes more uniform distribution of rhSOD and actually improved lung rhSOD delivery by $400 \%$. Less rhSOD delivered to the lungs in the rhSOD group probably implies more rhSOD remaining in the larger airways. The determination of a $25 \%$ decrease in oxidative injury in the rhSOD/PFC group suggests that the bulk of the oxidative damage in our model of ALI occurs in the peripheral regions of the lung.

Numerous studies have investigated whether SOD enzymes given either by injection or inhalation can protect lung tissue against oxidant injury. Most models have used Cu/Zn SOD, and intratracheal instillation has generally been shown to provide better protection than i.v. injection, although some conflicting results have been obtained (33-35). Recently recombinant human $\mathrm{Cu} / \mathrm{Zn}$ SOD has become available and intratracheal rhSOD has been shown to protect neonatal piglet lungs from damage from hyperoxia and mechanical ventilation (36). Furthermore, rhSOD was shown to rapidly incorporate into cells with a subsequent increase in lung SOD activity (37). In these studies, rhSOD was administered by instillation with saline or by aerosolization and did not distribute homo- geneously to the lungs (38). Here we show that PFC enhances rhSOD administration by facilitating higher plasma SOD concentrations, more optimal rhSOD lung distribution, and a better histologic profile. This might have additional pulmonary and systemic protective effects because lung inflammation has the potential to lead to systemic inflammation and possibly multiple system organ failure (39).

Most cells generate free radicals under normal conditions and increased amounts under conditions of stress. The first reactive oxygen species produced is the superoxide anion, and SOD is the only enzymatic system capable of degrading superoxide to hydrogen peroxide and water. Here we show that lung oxidative damage is decreased when rhSOD is delivered by PFC and that this finding could be due to a synergistic effect between rhSOD and PFC. Although, rhSODmediated decreases in oxidative damage seems a desirable target, we currently do not know whether this correlates necessarily with improved lung function. There could be many reasons for this incongruity. Although SOD has a central function in lung protection, many other antioxidant systems are active in the lung. For example, mitochondrial MnSOD has also been shown to be a key element in protection against injury (40). Furthermore, reactive oxygen species have recently been recognized to play a role in normal cell growth and signaling $(41,42)$. These complex interactions explain why it is always important to assess the relationship between oxidative stress and lung physiologic parameters. Despite these uncertainties, our data show that PFC optimizes the delivery of rhSOD after lung injury and that improved PFCmediated SOD distribution is associated with decreased lung oxidative injury.

In summary, the current study demonstrates an effective way to deliver SOD to the lungs of juvenile rabbits after ALI. The PFC-augmented SOD delivery enhances the antioxidant effects of the enzyme on the lungs. We speculate that this rhSOD delivery strategy might be critical in improving the antioxidant defenses of premature babies with acute lung disease and further improve long-term clinical pulmonary status.

Acknowledgments. The authors acknowledge the support of Barbara E. Gray, Administrative Manager, Nemours Research Lung Center, for her editing of this manuscript.

\section{REFERENCES}

1. Frank L 1985 Effects of oxygen on the newborn. Fed Proc 44:2328-2333

2. Crapo JD, Oury T, Rabouille C, Slot JW, Chang LY 1992 Copper, zinc superoxide dismutase is primarily a cytosolic protein in human cells. Proc Natl Acad Sci U S A 89:10405-10409

3. Weisiger RA, Fridovich I Superoxide dismutase: organelle specificity J Biol Chem 1973;248:3582-3592

4. Marklund SL 1982 Human copper-containing superoxide dismutase of high molecular weight. Proc Natl Acad Sci U S A 79:7634-7638

5. Wispe JR, Roberts RJ 1988 Bronchopulmonary Dysplasia. Blackwell Scientific, Cambridge, pp 103-116

6. Frank L, Price LT, Whitney PL 1996 Possible mechanism for late gestational development of the antioxidant enzymes in the fetal rat lung. Biol Neonate 70:116127

7. Asikainen TM, Ravio KO, Saksela M, Kinnula VL 1998 Expression and developmental profile of antioxidant enzymes in human lung and liver. Am J Resp Cell Mol Biol 19:942-949

8. McElroy MC, Postle AD, Kelly FJ 1992 Catalase, superoxide dismutase and 
glutathione peroxidase activities of lung and liver during human development. Biochim Biophys Acta 1117:153-158

9. Sosenko IR, Chen Y, Price LT, Frank L 1995 Failure of premature rabbits to increase lung antioxidant enzyme activities after hyperoxic exposure: antioxidant enzyme gene expression and pharmacologic intervention with endotoxin and dexamethasone. Pediatr Res 37:469-475

10. Freeman BA, Young SL, Crapo JD 1983 Liposome-mediated augmentation of superoxide dismutase in endothelial cells prevents oxygen toxicity. J Biol Chem 258:12534-12542

11. Walther FJ, Gidding CE, Kuipers IM, Willebrand D, Bevers EM, Abuchowski A, Viau AT 1986 Prevention of oxygen toxicity with superoxide dismutase and catalase in premature lambs. J Free Radic Biol Med 2:289-293

12. Rosenfeld WN, Davis JM, Parton L, Richter SE, Price A, Flaster E, Kassem N 1996 Safety and pharmacokinetics of recombinant human superoxide dismutase administered intratracheally to premature neonates with respiratory distress syndrome. Pediatrics 97:811-817

13. Davis JM, Rosenfeld WN, Richter SE, Parad MR, Gewolb IH, Spitzer AR, Carlo WA, Couser RJ, Price A, Flaster E, Kassem N, Edwards L, Tierney J, Horowitz S 1997 Safety and pharmacokinetics of recombinant human superoxide dismutase administered intratracheally to premature neonates with respiratory distress syndrome. Pediatrics 100:24-30

14. Davis JM, Richter SE, Biswas S, Rosenfeld WN, Parton L, Gewolb IH, Parad R, Carlo W, Couser RJ, Baumgart S, Atluru V, Salerno L, Kassem N 2000 Long-term follow-up of premature infants treated with prophylactic, intratracheal recombinant human CuZn superoxide dismutase. J Perinatol 20:213-216

15. Davis JM, Parad RB, Michele T, Allred E, Price A, Rosenfeld W North American Recombinant Human CuZnSOD Study Group 2003 Pulmonary outcome at 1 year corrected age in premature infants treated at birth with recombinant human $\mathrm{CuZn}$ superoxide dismutase. Pediatrics 111:469-476

16. Shaffer TH, Wolfson MR, Clark LC 1992 Liquid ventilation. Pediatr Pulmonol 14:102-109

17. Wolfson MR, Shaffer TH 1990 Liquid ventilation during early development: theory, physiologic processes and application. J Dev Physiol 13:1-12

18. Wolfson MR, Greenspan JS, Shaffer TH 1998 Liquid-assisted ventilation: an alternative respiratory modality. Pediatr Pulmonol 26:42-63

19. Cullen AB, Cox CA, Hipp SJ, Wolfson MR, Shaffer TH 1999 Intratracheal delivery of gentamicin with partial liquid ventilation. Respir Med 93:770-778

20. Wolfson MR, Greenspan JS, Shaffer TH 1996 Pulmonary administration of vasoactive substances by perfluorochemical ventilation. Pediatrics 97:449-455

21. Al-Rahmani A, Awad K, Miller TF, Wolfson MR, Shaffer TH 2000 Effects of partial liquid ventilation with perfluorodecalin in the juvenile rabbit lung after saline injury. Crit Care Med 28:1459-464

22. Jeng MJ, Trevisanuto D, Weis CM, Fox WW, Cullen AB, Wolfson MR, Shaffer TH 2001 Role of ventilation strategy on perfluorochemical evaporation from the lungs. J Appl Physiol 90:1365-1372

23. Mazzoni M, Nugent L, Klein D, Hoffman J, Sekins KM, Flaim SF 1999 Dose monitoring in partial liquid ventilation by infrared measurement of expired perfluorochemicals. Biomed Instrum Technol 33:356-364

24. Shaffer TH, Foust R, Wolfson MR, Miller TF 1997 Analysis of perfluorochemical elimination from the respiratory system. J Appl Physiol 83:1033-1040
25. Tütüncü AS, Faithfull NS, Lachmann B 1993 Comparison of ventilatory support with intratracheal perfluorocarbon administration and conventional mechanical ventilation in animals with respiratory failure. Am Rev Respir Dis 148:785-792

26. Wolfson MR, Greenspan JS, Deoras KS, Rubenstein SD, Shaffer TH 1992 Comparison of gas and liquid ventilation: clinical, physiological and histological correlates. J Appl Physiol 72:1024-1031

27. Jeng M-J, Yang S-S, Wolfson MR, Shaffer TH 2003 Perfluorochemical (PFC) combinations for acute lung injury: an in vitro and in vivo study in juvenile rabbits. Pediatr Res 53:81-88

28. Boynton BR, Carlo WA, Jobe AH 1994 New Therapies for Neonatal Respiratory Failure. Cambridge University Press, New York, p 185

29. Notter RH, Egan EA, Kwong MS, Holm BA, Shapiro DL 1985 Lung surfactant replacement in premature lambs with extracted lipid from bovine lung lavage: effect of dose, dispersion technique, and gestational age. Pediatr Res 19:569-577

30. Fox WW, Weis CM, Cox C, Farina C, Drott H, Wolfson MR, Shaffer TH 1997 Pulmonary administration of gentamicin during liquid ventilation in a newborn lamb lung injury model. Pediatrics 100:E5

31. Wolfson, MR Kechner, NE Roache, RF DeChadarevian, J-P Friss, HE Rubenstein, SD Shaffer, TH 1998 Perfluorochemical rescue after surfactant treatment: effect of perflubron dose and ventilatory frequency. J Appl Physiol 84:624-640

32. Forman HJ, Torres M 2002 Reactive oxygen species and cell signaling. Am J Respir Crit Care Med 166:S4-S8

33. Crapo JD, DeLong DM, Sjostrom K, Hasler GR, Drew RT 1977 The failure of aerosolized superoxide dismutase to modify pulmonary oxygen toxicity. Am Rev Respir Dis 115:1027-1033

34. Padmanabhan RV, Gudapaty R, Liener IE, Schwartz BA, Hoidal JR 1985 Protection against pulmonary oxygen toxicity in rats by the intratracheal administration of liposome-encapsulated superoxide dismutase or catalase. Am Rev Respir Dis 132:164-167

35. Turrens JF, Crapo JD, Freeman BA 1984 Protection against oxygen toxicity by intravenous injection of liposome-entrapped catalase and superoxide dismutase. $\mathrm{J}$ Clin Invest 73:87-95

36. Davis JM, Rosenfeld WN, Sanders RJ, Gonenne A 1993 Prophylactic effects of recombinant human superoxide dismutase in neonatal lung injury. J Appl Physiol 74:2234-2241

37. Das S, Horowitz S, Robbins CG, el-Sabban ME, Sahgal N, Davis JM 1998 Intracellular uptake of recombinant superoxide dismutase after intratracheal administration. Am J Physiol 274:L673-L677

38. Langenback EG, Davis JM, Robbins C, Sahgal N, Perry RJ, Simon SR 1999 Improved pulmonary distribution of recombinant human $\mathrm{Cu} / \mathrm{Zn}$ superoxide dismutase, using a modified ultrasonic nebulizer. Pediatr Pulmonol 27:124-129

39. Slutsky AS, Tremblay LN 1998 Multiple system organ failure. Is mechanical ventilation a contributing factor? Am J Respir Crit Care Med 157:1721-1725

40. Kinnula VL, Crapo JD 2003 Superoxide dismutases in the lung and human lung diseases. Am J Respir Crit Care Med 167:1600-1619

41. Jankov RP, Negus A, Tanswell AK 2001 Antioxidants as therapy in the newborn: some words of caution. Pediatr Res 50:681-687

42. Nathan C 2003 Specificity of a third kind: reactive oxygen and nitrogen intermediates in cell signaling. J Clin Invest 111:769-778 